\title{
Influence of water on ethanolic extraction yield of Azadirachta indica leaf
}

\begin{abstract}
For the solid-liquid extractions of plants such as neem (Azadirachta indica) happen, there must be a concentration gradient between two phases (solvent and solute). Thus, the moisture of the vegetable and the solvents used, such as hydroethanolic solutions, interfere in the production of crude extracts. Thus, the present work had the objective of the study of the solid-liquid extraction of solubles from the fresh neem leaf, evaluating the influence of hydroethanolic solvents. To determine moisture, the samples of fresh leaves $(\mathrm{n}=6)$ were dehydrated in an oven at $105^{\circ} \mathrm{C}$ according to the gravimetric method. The solid-liquid extracts were developed in laboratory cutter $(\mathrm{n}=3)$ with $93 \mathrm{~g}$ of neem "in natura" sheet, using ethyl alcohol P.A. $99.8^{\circ} \mathrm{GL}$ and hydroethanolic solutions 50 and $20^{\circ} \mathrm{GL}$. The results obtained show that the dry extract produced by extraction with ethyl alcohol PA $99.8^{\circ} \mathrm{GL}$ was $231.4 \%$ higher when compared with that obtained with the $50^{\circ} \mathrm{GL}$ hydroethanol solution and $242.6 \%$ higher when compared with the $20^{\circ} \mathrm{GL}$ hydroethanolic solution, demonstrating the importance of solvent selection and the influence of water on the extraction of soluble vegetables.
\end{abstract}

Keywords: solid-liquid extraction, crude extract, hydroethanolic extract, neem

\author{
Volume 8 Issue 2 - 2019
}

\section{Cleidenely Evangelista Franco Borges,' Elizabeth Uber Bucek,, ${ }^{1,2}$ Mariângela Terra} Branco Camargos, ${ }^{3}$ José Roberto Delalibera Finzer ${ }^{l}$

'Department of Chemical Engineering, University of Uberaba, Brazil

${ }^{2}$ Department of Pharmaceutical Sciences, University of Uberaba, Brazil

${ }^{3}$ Agronelli Institute of Social Development - IADES, Uberaba, Brazil

Correspondence: Elizabeth Uber Bucek, Department of Chemical Engineering and Pharmaceutical Sciences, University of Uberaba, 38050-50I Uberaba, MG, Brazil, Email elizabeth.bucek@uniube.com

Received: March 19,2019 | Published: April 16,2019

\section{Introduction}

The solid-liquid extraction occurs when there is mass transfer due to the existence of a concentration gradient between two phases, in which the soluble is extracted by entering in contact with a solvent. ${ }^{1}$ With that, the yield of the leaf extracts of the Azadirachta indica is directly correlated with the solvent used, once, as demonstrated by Fick's second Law, as shown in Equation 1, the diffusion rate will be higher, the greater the concentration variation between the phases..$^{2-4}$

$$
\frac{\partial C A}{\partial t}=D a b \nabla^{2} C A
$$

Different solvents are used to obtain crude extract of dry leaves of $A$. indica. The extraction of total soluble from the fresh leaves is little studied, and they are usually used frequently in rural properties. Dried leaves extracted with N, N-Dimethylformamide, present antibacterial activity in Staphylococcus aureus and Escherichia coli, suggesting the incorporation of the extract in packages giving antibacterial activity in this material. ${ }^{5}$ The ethanolic extract of the dried leaves shows cicatrizant effect in the colitis induced in rats and antibacterial activity against Escherichia coli ATCC 25922, Shigella boydii, Shigella sonnei and Shigella flexneri, present in the intestine. ${ }^{6}$ On the other hand, the aqueous extracts of the dried leaves present a non-sticky effect of Candida albicans, suggesting their use in the prevention of diseases of the oral cavity. ${ }^{7}$ The Brazilian population uses hydroethanolic extractions of fresh neem leaves, because it is simpler and more economical in relation to the dry leaves extract, which justifies this study.

\section{Neem sheet moisture}

It was used $9 \mathrm{~g}$ of neem fresh leaves, which were taken to the oven at $105^{\circ} \mathrm{C}$, to determine the humidity, through the difference between the mass of the fresh leaf and the mass of the dehydrated leaf (constant mass), according to gravimetric method of humidity, ${ }^{8}$ where it was obtained a content of humidity of $75.03 \%$, with a coefficient of variation of $1.34 \%$.

\section{Solid-liquid extraction}

The solid-liquid extractions $(400 \mathrm{~mL}$ solvent/extraction) were performed in batch with the use of cutter (10L). The solvents used was the ethyl alcohol P.A. $99.8^{\circ} \mathrm{GL}$ and the hydroethanolic solutions of 50 and $20^{\circ} \mathrm{GL}$, prepared with deionized water and measured with Gay Lussac alcoholometer.

For these extractions, $93 \mathrm{~g}$ of fresh neem leaves were used. The solvents of the extracts obtained were evaporated at $40^{\circ} \mathrm{C}$, followed by dehydration in an oven at $105^{\circ} \mathrm{C}$ for 48 hours, and weighed in analytical balance. It was decided to use the vegetable neem in natura, since the active compound, azadirachtin, degrades at a temperature above $40^{\circ} \mathrm{C}$. In addition, farmers use fresh neem leaf for direct application. After the extractions, the ethanol P.A. $99.8^{\circ} \mathrm{GL}$ had extracted $1.754 \pm 0.182 \mathrm{~g}$ of dry extracts. The $50^{\circ} \mathrm{GL}$ hydroethanolic solution extracted $0.758 \pm 0.050 \mathrm{~g}$ and the $20^{\circ} \mathrm{GL}$ hydroethanolic solution extracted $0.723 \pm 0.069 \mathrm{~g}$, according to Table 1 . The results demonstrated are in accordance with the studies carried out by Chaudhary et al., ${ }^{9}$ in which the active components of the neem vegetable have been shown to have little solubility in water and high solubility (and may be complete) in organic solvents such as alcohols, hydrocarbons, ethers and ketones (Table 1).

In addition, it is noted that the amount of dry extract obtained with the hydroethanolic solution $50^{\circ} \mathrm{GL}(0.758 \pm 0.050 \mathrm{~g})$ relative to the $20^{\circ} \mathrm{GL}$ hydroethanolic solution $(0.723 \pm 0.069 \mathrm{~g})$ was very close. In view of this, the use of the $20^{\circ} \mathrm{GL}$ hydroethanolic solution is indicated for the cost reduction of the extraction stage, with the commercial value of the water being lower than that of ethanol. 
Table I Relationship of dry extracts obtained with alcohol and hydroethanolic solutions $\left(99.8,50.0\right.$ and $\left.20.0^{\circ} \mathrm{GL}\right)$ in the industrial cutter

\begin{tabular}{lllll}
\hline \multirow{2}{*}{ Solvent } & \multicolumn{5}{c}{ Dry extract (g) } \\
\cline { 2 - 5 } & $\mathbf{n ~ I}$ & $\mathbf{n 2}$ & $\mathbf{n 3}$ & average (g) \\
\hline Ethyl alcohol P.A. $99.8^{\circ} \mathrm{GL}$ & $\mathrm{I} .740$ & 1.535 & 1.989 & $1.754 \pm 0.182$ \\
$50^{\circ} \mathrm{GL}$ hydroethanolic solution & 0.787 & 0.701 & 0.787 & $0.758 \pm 0.050$ \\
& & & & \\
$20^{\circ} \mathrm{GL}$ hydroethanolic solution & 0.767 & 0.758 & 0.644 & $0.723 \pm 0.069$ \\
\hline
\end{tabular}

\section{Conclusion}

The water content in hydroethanolic solutions influences the yield of the solid-liquid extraction when compared to the extracts obtained from the use of ethyl alcohol P.A. $99.8^{\circ} \mathrm{GL}$. As the extracts are formed mainly from organic compounds, they are better solubilized by organic solvents, such as ethyl alcohol P.A. $99.8^{\circ} \mathrm{GL}$ as demonstrated in the results obtained in this study.

The study of the influence of the water in obtaining the crude extract is necessary since the leaves of the vegetable can be used in fresh form, the water present in the vegetable becomes part of the composition of the extraction solvent, when miscible, interfering in the types of total extractable solids.

\section{Acknowledgments}

FAPEMIG - Minas Gerais Research Support Foundation, Brazil.

\section{Conflicts of interest}

The authors declares there is no conflicts of interest.

\section{References}

1. Treybal RE. Mass-transfer operations. 3rd ed. London: McGraw-Hill; 1980: 784

2. Neves EJM, Carpanezzi AA. O cultivo do nim para produção de frutos no Brasil Colombo, PR: Circular Técnica 62 EMBRAPA. 2008;162:1-8.

3. Bird RB, Stewart WE, Lightfoot EN. Fenómenos de transporte. 2nd ed. México: Limusa Wiley; 2006: 1062.

4. Bergs D, Merz J, Delp A et al. Standard procedure for the selection of solvents for natural plant extraction in the early stages of process development. Chemical Engineering \& Technology. 2013;36(10):17391748 .

5. Mahendran R, Sridharan D, Arunmozhidevan C, et al. Fabrication and Antibacterial Effects of Polycarbonate/Leaf Extract Based Thin Films. Journal of Materials. 2016:1-7.

6. Gautam M, Goel S, Ghatule R, et al. Azadirachta indica attenuates colonic mucosal damage in experimental colitis induced by trinitrobenzene sulfonic acid. Indian J Pharm Sci.. 2013;75(5):602-606.

7. Polaquini SRB, Svidzinski TIE, Kemmelmeier C, et al. Effect of aqueous extract from Neem (Azadirachta indica A. Juss) on hydrophobicity, biofilm formation and adhesion in composite resin by Candida albicans. Arch Oral Biol. 2006;51(6):482-490.

8. Farmacopeia Brasileira. 5th ed. Brasília: ANVISA; 2010: 545.

9. Chaudhary S, Kanwar RK, Sehgal A, et al. Progress on Azadirachta indica based biopesticides in replacing synthetic toxic pesticides. Front Plant Sci. 2017;8(610):1-13. 